\title{
The Effective Analysis of College Employment Guidance
}

\author{
Zhiqiong Guo, Bing Bai \\ Business school, Jiangsu normal university, Xuzhou, Jiangsu China (szzxbb@163.com)
}

\begin{abstract}
Employment guidance for college students should be integrated and personalized. This paper explores the various influence factors of College Students' employment guidance through the investigation into 300 university graduates in Xuzhou City, Jiangsu Province, and analyzes the demand of career guidance for college students, and thus provides a reference for the effectiveness work of college students' employment guidance.
\end{abstract}

Keywords — college students, universities, employment guidance

\section{大学生就业指导实效性分析}

\author{
郭志琼 白冰 \\ 江苏师范大学商学院, 徐州, 江苏, 中国
}

摘 要 高校大学生就业指导应该是全程化、个性化的指导, 本研究通过对江苏省徐州市 300 名高校应届大学毕业生调查, 探讨 影响大学生求职的各类因素, 分析大学生对高校就业指导的需求, 进而为高校大学生就业指导的实效性工作开展提供参考。

关键词 大学生, 高校, 就业指导

\section{1. 引言}

高校毕业生是社会稳定发展的宝贵人才资源, 高校毕 业生人数逐年递增的趋势 (图 1 所示), 使得社会就业压力不 断增加, 2014 年全国普通高校毕业生规模达 727 万，做好 高校毕业生的就业创业工作, 有利于就业形势的稳定和经 济社会健康发展。

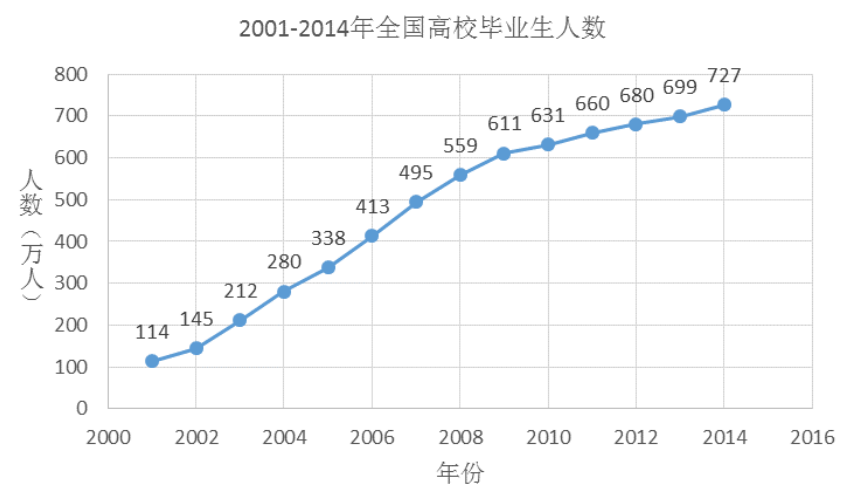

图 1 中国 2001-2014 年高校毕业生人数

国家社会科学基金教育学项目(No.CIA130172)
帮助大学生就业需要政府、社会、企业、高校、学生 及其家庭等多方参与, 形成合力。而对于高校而言, 在提 高人才培养质量和提升就业竞争力方面必须增强高等教育 与社会需要的适应性, 扎实做好大学生就业指导工作。就 业指导的工作如何切合经济社会的需求趋势, 如何使高校 就业指导工作与人才培养相匹配, 进而使就业指导工作卓 有成效便成为亟待解决的问题。

本研究在文献研究的基础上, 2014 年 5 月对江苏省徐 州市 2014 届毕业生进行调查, 发放调查问卷 300 份, 回收 有效问卷 290 份。在调查过程中, 发现学校提供的就业指 导和大学生的需求存在一定程度上的差距, 如: 就业指导 的内容和形式都较简单, 并不能有效满足大学生日趋多样 化、个性化的需求; 由于人员、经费等各种原因, 高校就 业指导的全程化、个性化工作实施情况并不理想; 就业指 导工作实践落后于现实需求等。针对调查的情况, 我们一 方面应该在政策上给予就业指导工作更大力度的支持, 以 利于大学生就业指导工作能够得到有效落实; 另一方面, 从大学生需求角度出发, 对高校就业指导工作进行准确定 位, 真正使就业指导工作真正卓有成效, 促进高校就业工 作的健康发展。 


\section{2. 大学生对就业形势的态度}

根据大学生对就业形势的态度和看法我们可以了解到 大学生在面对就业时的心理及其自信心。在一定程度可以 为就业指导工作提供一种引导思路, 以利于更好的对大学 生日常培养和心理引导。

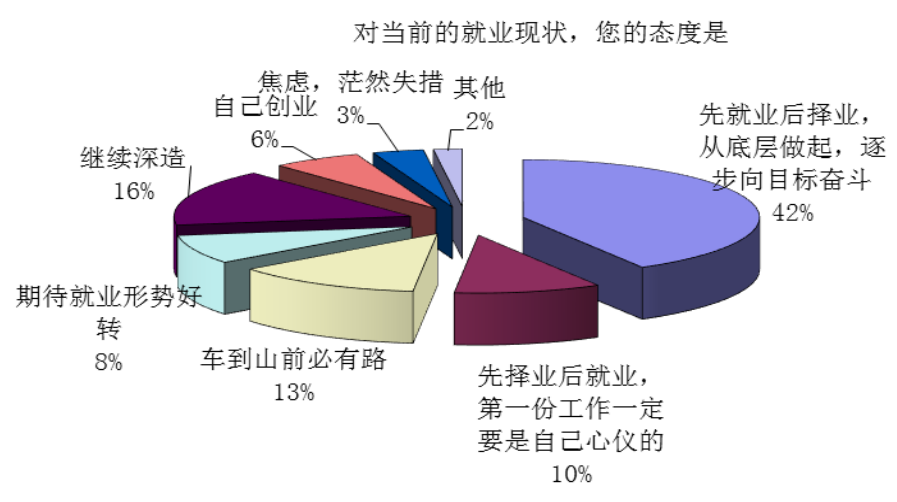

图 2 高校大学生对就业现状的态度

对 290 名应届毕业生的调查中发现 (图 2 所示), 有 191 位大学生表示 “先就业后择业, 从底层做起, 逐步向 目标奋斗”, 占全部受调查大学生的 $42 \%$; 有 73 位大学生 选择继续深造, 占受调查大学生的 $16 \%$, 有 28 位选择自己 创业, 占 $6 \%$ 。可以看出大多数大学生面对就业是比较理性 的, 超过一半的同学较好的为自己做了恰当的定位, 但也 有 $13 \%$ 的大学生抱着 “车到山前必有路” 的心态, 没有积 极的心态; 近 $10 \%$ 的大学生茫然失措, 或者是期待就业形 势的好转, 没有能够积极地因对, 这就需要就业工作指导 的老师可以给予适当的培养和引导, 帮助这部分同学可以 尽快提高自己的就业竞争力，以更积极的心态对待就业。

\section{3. 教学环节对大学生就业的影响因素}

专业能力是大学生就业能力中最基本的能力, 也是用 人单位招聘人员时首要考察的能力。大学生应该通过高等 教育的学习, 掌握并具备专业理论知识以及相应的实践能 力, 并能够运用于工作岗位中。专业的能力决定了大学生 是否能够胜任和完成用人单位对其分配的工作任务, 专业 能力是大学生进入职场必须具备的基本能力。

\section{在求职中您如何看待专业和工作性质的关系}

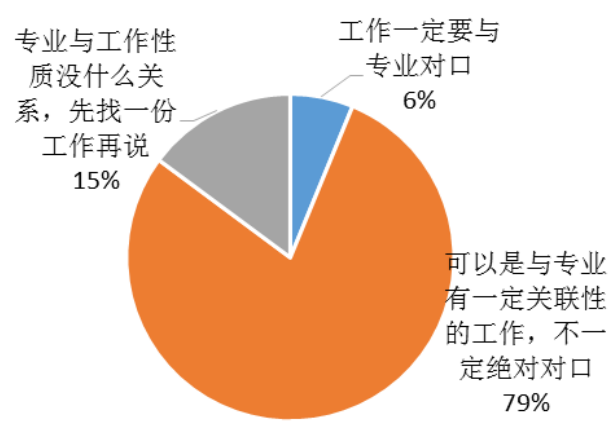

图 3 大学生对专业和工作性质关系的看法

图 3 所示, 290 位大学生中有 229 人表示自己的第一 份工作可以是与专业有一定关联性的工作, 不一定绝对对 口, 占 79\%; 6\% 的大学生认为工作必须要与专业对口。 $85 \%$ 的大学生表示专业要与未来的工作对口, 从一定程度上可 以看出, 专业对于大学生而言与未来的就业方向存在非常 大的关联性, 学好专业对于大学生未来就业发展起到了非 常大的基础性作用, 就业指导工作的落实的一个非常重要 的方面便是要引导学生认真学好本专业课程, 同时拓展自 己的知识面, 为未来的就业打下良好的基础。

\section{您认为在校期间哪些环节对您帮助最大}

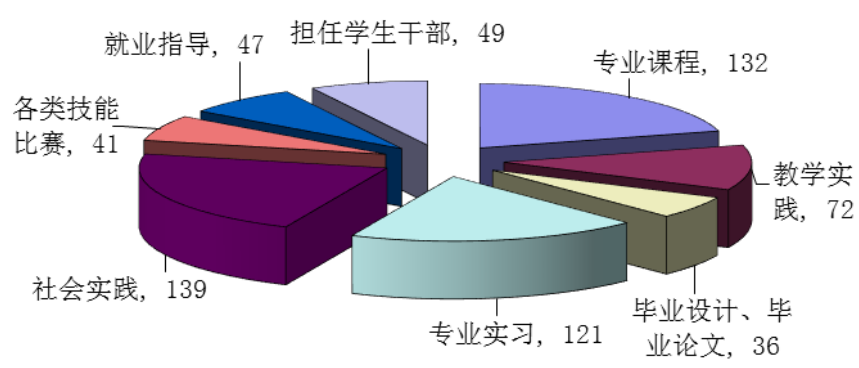

图 4 大学生对在校期间各类教学环节的认可度

如图 4 所示, 对 290 位大学生的调查 (每位大学生可 选择 2-3 种对自己帮助最大的教学环节) 发现, 大学教学 环节中对大学生帮助最大的前三位是: 专业课程的学习、 社会实践以及专业实习, 这也充分说明了, 专业能力对大 学生而言是最基础和重要的能力, 对大学生的就业指导, 首先要引导大学生充分重视专业课程的学习和实践能力的 提升。

\section{4. 大学生对就业指导的需求分析}

在对 290 位应届大学生的调查中, 有 234 人表示在就 业过程中需要高校就业指导, 占 $87.7 \%$, 有 56 人表示无所 
谓。大多数大学生表示, 如果就业指导能够更加实用和有 针对性的话, 对其帮助会很大, 他们希望能够通过就业指 导提升自身的就业能力, 为进入职场做好准备。表示对就 业指导无所谓的 56 人中, 大多是大学生也表示, 还是对就 业指导充满期待的, 但目前就业指导面对全体同学, 有些 流程化, 针对性不强, 希望就业指导能够更具个性化和针 对性。

图 5 和图 6 给出了大学生为就业做的各种准备以及对 高校就业指导工作的需求情况。

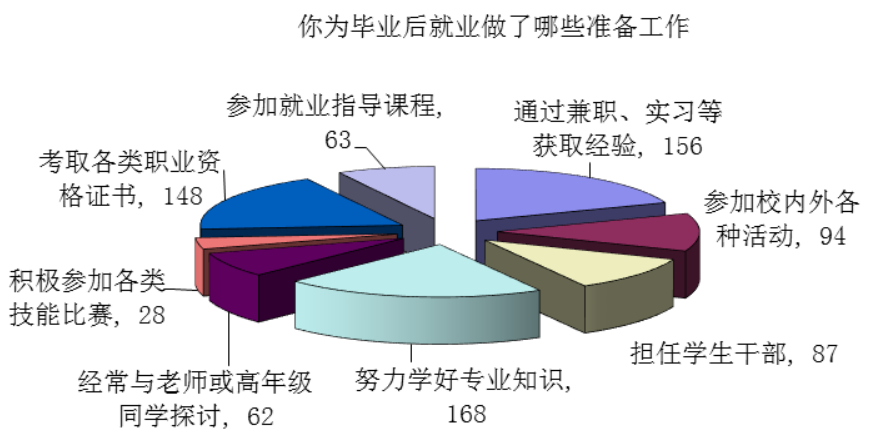

图 5 大学生为就业做的准备工作

如图 5 所示, 290 位被调查的大学生中有 168 人表示 专业知识扎实, 156 人已经通过兼职、实习等获得了各类 经验, 148 人通过性表示已经考取了各类职业资格证书, 94 人表示参加校内外各种活动提高了自己的能力, 87 位大 学生担任学生干部, 62 位大学生经常与老师或高年级同学 探讨, 63 位认为通过就业指导课程的学习为就业做了准备。 可以看出, 大多数大学生通过大学阶段的各种努力为进入 职场前做了准备, 而其中专业知识和实践创新是最为重要 的两个环节, 这也与用人单位对大学生的要求不谋而合, 在此基础上, 大学生应该努力提高自身的综合素质, 如人 际交往, 学习和分析问题的能力等。

您最希望在高校就业指导中获取哪方面信息

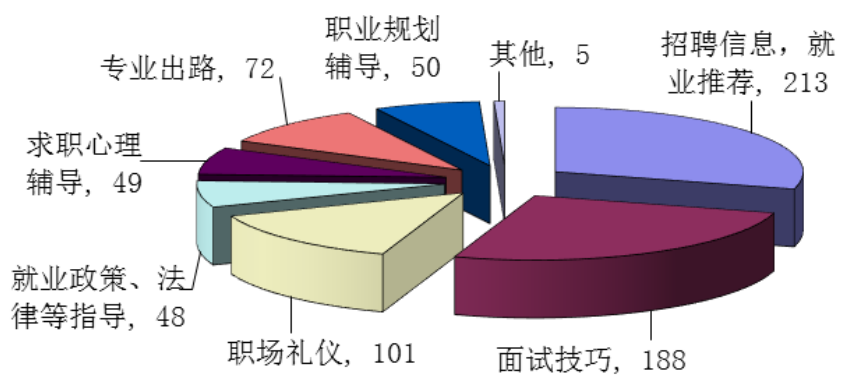

图 6 大学生对就业指导内容的需求倾向

290 位大学生中 213 人表示希望通过就业指导获得招
聘信息、就业推荐等; 188 人希望获得面试技巧; 101 人认 为求职以及进入职场, 礼仪的训练很重要, 希望可以在就 业指导课程上系统学习。同时也有不同比例的同学表达了 对职业规划辅导, 就业政策、法律等的指导, 求职心理等 方面的需求。从大学生的意愿可以看出, 大学生对系统的 就业指导有着非常大的需求, 从入学的职业生涯规划到专 业学习的引导, 从实践创新能力的提升到求职技巧的训练, 大学生能够顺利进入职场并有优异的表现, 就业指导的作 用不可忽视。这同时也要求就业指导必须更加实用性、针 对性、系统性。

\section{5. 建议}

高校的就业指导工作对于人才培养, 满足社会对人才 的需求, 起着重要的作用。本文通过对 290 位应届毕业生 的调查研究, 从大学生就业需求的角度探索就业指导工作 的实效性建议和做法, 促进高校就业指导工作的有效落实。

(1) 注重全程指导。大学生就业指导不仅仅是大学生 的大三、大四阶段才要进行的工作, 而是贯穿整个大学生 大学四年。从进入大学开始直至毕业, 在不同的年级, 对 大学生进行不同的指导, 如大一的职业生涯规划定位, 大 二的实践指导，大三的就业信息分析，大四的就业技巧训 练等, 各年级有其阶段性的辅导重点。

（2）注重个性化指导。大学生个性不同, 知识结构不 同, 在就业过程中遇到的问题也会是多种多样的, 因此就 业指导工作必须是全方位提供个性化的就业指导, 只有这 样就业指导工作才能真正做到不流于形式, 才能服务好每 一位大学生, 切实提高大学生的核心竞争力和就业能力。

（3）就业指导内容实用全面。就业指导不能是泛泛指 导, 而是要内容全面而实用, 如开设就职培训以提高学生 应聘技巧, 增强就业竞争力; 进行模拟训练和各类讲座, 以了解职业要求和特点; 组织社会实践活动, 增强大学生 的就业适应性等。另外, 还应该开设有针对性的面试技巧、 礼仪、求职心理调适辅导等。就业指导内容实用性要强, 学生易于接受, 而不能仅仅是落于形式。

（4）培养大学生实践创新能力和创业能力。实践创新 能力是社会和用人单位对大学生提出的普遍要求, 培养大 学生实践创新能力是高校教育工作的一个重要环节, 高校 必须加强与用人单位的合作, 组织和鼓励大学生积极参加 各类社会实践创新活动。大学生的实践创新能力的提升有 利于增强大学生的核心竞争力和就业能力。

（5）就业指导队伍必须专业化。高校的就业指导人员 必须具有高素质、专业化, 具有相应的学位、专业以及资 格, 并拥有一定的经验, 同时, 要有计划地进行系统定期 培训、学习和提高。只有这样才能真正有效的对大学生进 
行相应的就业指导, 对大学生进行科学的引导和帮助。

\section{参考文献(References)}

[1] Zhao Feng, On the Current Status and Problems of Colleges and Universities Employment Guidance, university education science, vol. 123, no. 5, pp. 90-95, 2010.

[2] Yue Chancejun, Yang Zhongchao, The Research on Employment Outcome of College Graduates and Its Influential Factors in China, Journal of higher education, vol. 33, no.4, pp.35-44, 2012.
[3] Gong Yicheng, Li Deyi, Lv Xuhua, Practice and Simulation of the Risk Decision in Guidance of College Students' Employment, Journal of Higher Education Management, vol.7, no.4, pp.119-124, 2013.

[4] Wang Junping, College Students' Professional Ability from the Perspective of Employers, Journal of Higher Education, vol.34, no.5, pp.72-75, 2013.

[5] Liu Xuemei, The Influence of College Students' Value of Career Success on Employment Intention, Journal of higher education ,vol.34, no.5, pp.76-82, 2013. 